\title{
Evaluation of Gender in Living Male and Female Children Through the Measurement of Sternum Bone in the Population of Uttar Pradesh
}

\author{
S V Sharma ${ }^{1}$, A K Pankaj ${ }^{2}$, Navneet Kumar ${ }^{3}$, Nilesh ${ }^{4}$, H B Sharma ${ }^{5}$ \\ ${ }^{1}$ Resident, Department of Anatomy, King George's Medical University, U.P., Lucknow, ${ }^{2}$ Associate Professor, Department of Anatomy, King George's \\ Medical University, U.P., Lucknow, ${ }^{3}$ Professor \& Head, Department of Anatomy, King George's Medical University, U.P., Lucknow, ${ }^{4}$ Laboratory Assistant , \\ Department of Medicine, King George's Medical University, U.P., Lucknow, ${ }^{5}$ Ward Master, Department of Obstetrics \& Gynecology, King George's \\ Medical University, U.P., Lucknow.
}

\section{Abstract}

Introduction: Sex evaluation from the skeletal remains is of very much important for medicolegal aspects in the field of medical science. On the basis of previous researcher, I have been planned to verify the existrnal data and establish them in reference to population in and around Lucknow. With the help of this study we were distinguishes the male and female sternum bone in children. Subjects and Methods: The technique described by Ashley GT -1956b was used for measurement of sternum. Each linear measurement has been taken thrice on the anatomical position of the sternum using Mitutoyo-digital vernier calipers to the nearest millimeter with precision of $0.01 \mathrm{~mm}$. Results: Discussion: The previous researchers told that the sternum has distinguished in different zone of India, and it is shorter than European country. Our findings of manubrium were $49.45 \pm 3.45 \mathrm{~mm}$ for male and $44.47 \pm 5.79 \mathrm{~mm}$ for female children respectively. The study done by previous researcher was provided full support to our present finding. Conclusion: The comparison of mean length of manubrium, mesosternum and sternum between 2 to $15 \mathrm{yrs}$, female and male sternum between two groups, significantly different and higher length of manubrium, mesosternum and sternum in males as compared to females children.

Keywords: Morphometry of Sternum Gender determination Size of Manubrium Size of Mesostenum.

Corresponding Author: Dr. Arvind Kumar Pankaj, Associate Professor, Department of Anatomy, King George's Medical University, U.P., Lucknow. E mail : drarvindpankajcsmmu@yahoo.com

Received: February 2019

Accepted: February 2019

\section{Introduction}

To identify the sex of the specimen found, with great accuracy and precision, is of utmost importance. The bones are more resistant to the putrification process that makes it important to study, which in turn helps to identify the gender determination criteria. Next to pelvis, human skull is regarded as the most accurate indicator of the sex [Macaluso PJ et al., 2014] but when these bones are missing; ${ }^{[1]}$ recent findings have suggested that sternum and manubrium can act as valuable specimens [Dwight T- 1881 \& Osunwoke EA et al. - 2010] Manubriosternum is a flat bone that takes part in the formation of the thoracic cage. ${ }^{[2,3]}$ Dwight T- 1881 Suggested that the male sternum is considerably longer than the female sternum. He also confirmed that the combined length of manubrium and mesosternum, and the total sternal length provide useful guide to the height of an individual. Similarly, [Torwalt et al., 2005] studied the sex differentiation in human sternum by studying its various morphometric measurements in various populations. ${ }^{[4]}$

In India, various researchers have presented their work on the sternum regarding sex determination. ${ }^{[5,6]}$ [Singh et al., \& Dahiphale VP et al., 2002] Identification is recognition of an individual by means of various physical features and biological parameters, which are unique to each individual. Since the bone resists putrefaction and destruction by animals, they can be used for identification and can lead to a reliable determination of age, sex, race [Camps FE et al., 1976] stature of the individual. ${ }^{[7]}$

Sex determination from unknown human skeletal remains or decomposed bodies is an important initial step in forensic investigation. Accurate determination of skeletal sex is a critical requirement in medico legal cases. Sternum is highly useful for determination of sex of an individual apart from determination of racial characters. Studies on sternum have been reported in both sexes of American, African and European population and also in different zones of Indian population like North Indian, Maharashtra and Guajarati population but they are scanty.

This study has been planned to verify the existrnal data and establish them in reference to population in and around Lucknow. Since the study was conducted in the people of Lucknow, and subjects were selected only from in and around the Lucknow as the race and built may affect the dimensions of the sternum. By this study we evaluated the growth and size of sternum in living male and female children and also find out the relation between the size of 


\section{Sharma et al; Evaluation of Gender Through the Measurement of Sternum Bane}

sternum and sexes.

In the present study, an effort has been made to estimate sex through the measurement of sternums bone in living male and female children requited from department of medicine as well as pediatrics, obstetrics \& gynecology and Department of Anatomy, King George's Medical University, U.P., Lucknow.

\section{Subjects and Methods}

This study has been conducted on the total 100 subjects, 50 female (0-15 yrs) and 50 male (0-15yrs) of healthy people (Living children) from general population of north India as well as in and around the Lucknow. After obtaining ethical clearance and informed consent form, the living subjects have been recruited from the healthy staff members of OPD, department of medicine, pediatrics and Obstetrics \& gynecology at King George's Medical University, U P, Lucknow. All the living subjects have been well informed about the nature of study. To prevent discrimination, living subjects have recruited for our study fulfilling inclusion criteria (male and female, age 0 to 15 years, BMI less than 25 and no history of chronic disease, at least 1 years tenure, no use of medication other than analgesics during the month preceding data collection). The living subjects have been explained the procedure of study.

For the morphometry of the sternum, following measurements have been taken in to consideration:

\section{Length of manubrium:}

It has been measured from the centre of suprasternal notch to the centre of the manubrio-sternal junction in mid sagittal plane.

\section{Length of mesosternum:}

It has been measured from the centre of manubrio-sternal junction to the centre of sterno-xiphoid junction in the mid sagittal plane.

\section{Total length of sternum:}

It has been measured from the centre of jugular notch to xiphoid process in the mid sagittal plane.The above mentioned measurements have been further use to calculate various sternal dimensions and indices according to the technique described by Ashley. Each linear measurement has been taken thrice on the anatomical position of the sternum using Mitutoyo-digital vernier calipers to the nearest millimeter with precision of $0.01 \mathrm{~mm}$, according to definitions presented in and their average was recorded. ${ }^{[10]}$

\section{Results}

\section{Basic characteristics:}

The present study deals evaluation of sex determination through measurement of human sternum in Lucknow city of Uttar Pradesh (U.P.). The primary outcome measures of the study were length of manubrium, length of mesosternum and length of sternum measured in millimeter $(\mathrm{mm})$. Besides that actual age (yrs), height $(\mathrm{cm})$, weight $(\mathrm{kg})$, chest circumference $(\mathrm{cm})$, waist circumference and hip circumference $(\mathrm{cm})$ were also noted.

\section{Female 2-15 yrs:}

The basic characteristics of 2-15 yrs females are summarized in Table 1. The mean length of manubrium, mesosternum and sternum ranged from 34.65-58.90 mm, 70.37-108.56 $\mathrm{mm}$ and $110.24-148.29 \mathrm{~mm}$ respectively with mean $44.47 \pm$ $5.79 \mathrm{~mm}, 93.90 \pm 7.92 \mathrm{~mm}$ and $138.38 \pm 6.93 \mathrm{~mm}$ respectively and median $43.17 \mathrm{~mm}, 95.38 \mathrm{~mm}$ and 138.55 $\mathrm{mm}$ respectively.

\section{Male 2-15 yrs:}

The mean length of manubrium, mesosternum and sternum ranged from 39.57-56.71 $\mathrm{mm}$, 95.02-121.54 $\mathrm{mm}$ and $149.23-168.76 \mathrm{~mm}$ respectively with mean $49.45 \pm 3.45$ $\mathrm{mm}, 106.71 \pm 6.25 \mathrm{~mm}$ and $156.16 \pm 5.26 \mathrm{~mm}$ respectively and median $49.62 \mathrm{~mm}, 105.58 \mathrm{~mm}$ and $156.38 \mathrm{~mm}$ respectively.

\section{Comparison between Female vs. Male- 02-15 yrs:}

The comparison of mean length of manubrium, mesosternum and sternum between 2 to 15 yrs female and male is summarized in Table 3 and also depicted in Fig. 1 to 3 respectively. Comparing the mean length of manubrium, mesosternum and sternum between two groups, Student's t test showed significantly different and higher length of manubrium $(10.1 \%)(44.47 \pm 5.79$ vs. $49.45 \pm 3.45, \mathrm{t}=5.23$, $\mathrm{p}<0.001)$, mesosternum $(12.0 \%)(93.90 \pm 7.92$ vs. $106.71 \pm$ $6.25, \mathrm{t}=8.98, \mathrm{p}<0.001)$ and sternum $(11.4 \%)(138.38 \pm 6.93$ vs. $156.16 \pm 5.26, \mathrm{t}=14.45, \mathrm{p}<0.001)$ in males as compared to females.

Table 1: Basic characteristics of 2-15 yrs females

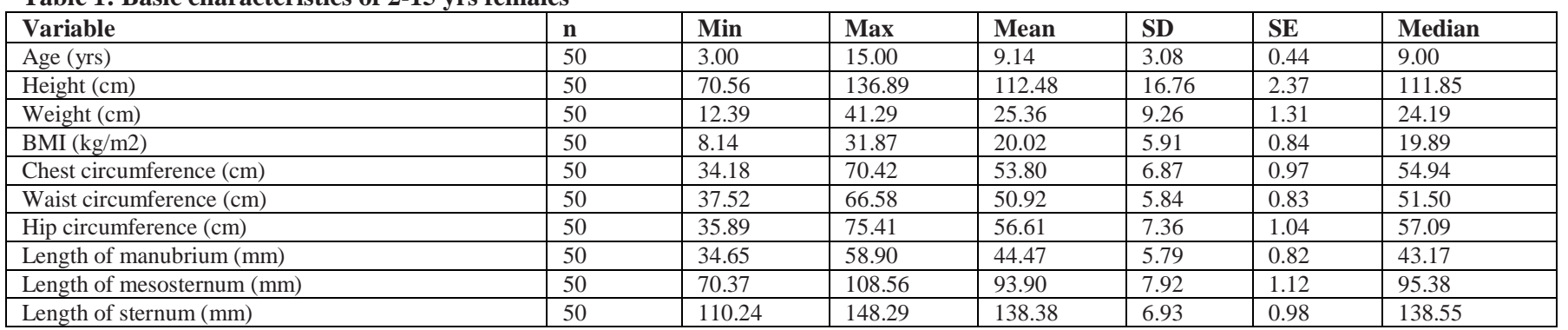


Sharma et al; Evaluation of Gender Through the Measurement of Sternum Bane

Table 2: Basic characteristics of 2-15 yrs males

\begin{tabular}{|c|c|c|c|c|c|c|c|}
\hline Variable & n & Min & Max & Mean & SD & SE & Median \\
\hline Age (yrs) & 50 & 3.00 & 15.00 & 9.40 & 2.95 & 0.42 & 9.00 \\
\hline Height $(\mathrm{cm})$ & 50 & 78.69 & 158.39 & 129.87 & 18.91 & 2.67 & 129.82 \\
\hline Weight $(\mathrm{cm})$ & 50 & 3.19 & 41.39 & 29.62 & 8.94 & 1.26 & 30.52 \\
\hline BMI (kg/m2) & 50 & 2.06 & 39.38 & 17.77 & 5.57 & 0.79 & 16.72 \\
\hline Chest circumference $(\mathrm{cm})$ & 50 & 46.37 & 68.36 & 56.94 & 5.43 & 0.77 & 57.07 \\
\hline Waist circumference $(\mathrm{cm})$ & 50 & 42.36 & 64.23 & 53.03 & 5.31 & 0.75 & 52.96 \\
\hline Hip circumference $(\mathrm{cm})$ & 50 & 40.63 & 80.84 & 58.26 & 7.02 & 0.99 & 58.36 \\
\hline Length of manubrium (mm) & 50 & 39.57 & 56.71 & 49.45 & 3.45 & 0.49 & 49.62 \\
\hline Length of mesosternum (mm) & 50 & 95.02 & 121.54 & 106.71 & 6.25 & 0.88 & 105.58 \\
\hline Length of sternum (mm) & 50 & 149.23 & 168.76 & 156.16 & 5.26 & 0.74 & 156.38 \\
\hline
\end{tabular}

Table 3: Comparison of length of manubrium, mesosternum and sternum (Mean $\pm \mathrm{SD}, \mathrm{n}=50$ ) between 2 to 15 yrs female and male

\begin{tabular}{|c|c|c|c|c|}
\hline Variable & Female & Male & t value & $p$ value \\
\hline Length of manubrium (mm) & $44.47 \pm 5.79$ & $49.45 \pm 3.45$ & 5.23 & $<0.001$ \\
\hline Length of mesosternum (mm) & $93.90 \pm 7.92$ & $106.71 \pm 6.25$ & 8.98 & $<0.001$ \\
\hline Length of sternum (mm) & $138.38 \pm 6.93$ & $156.16 \pm 5.26$ & 14.45 & $<0.001$ \\
\hline
\end{tabular}

Length of manubrium $(\mathrm{mm})-2$ to $15 \mathrm{yrs}$

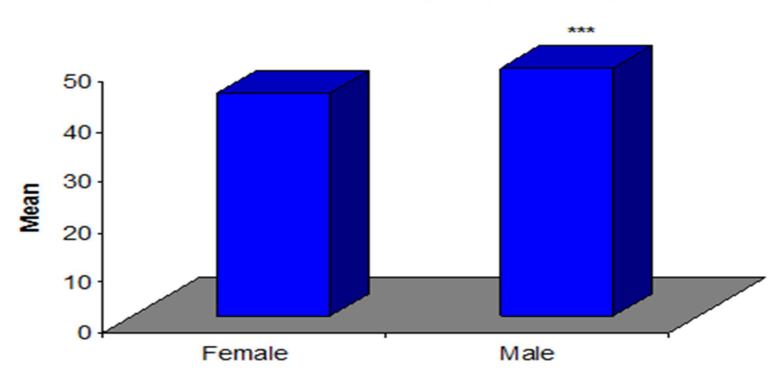

Figure 1: Comparison of length of manubrium between 2 to 15 yrs females and males.

**** $\mathrm{p}<0.001$ - as compared to Female

Length of mesosternum ( $\mathrm{mm})-2$ to $15 \mathrm{yrs}$

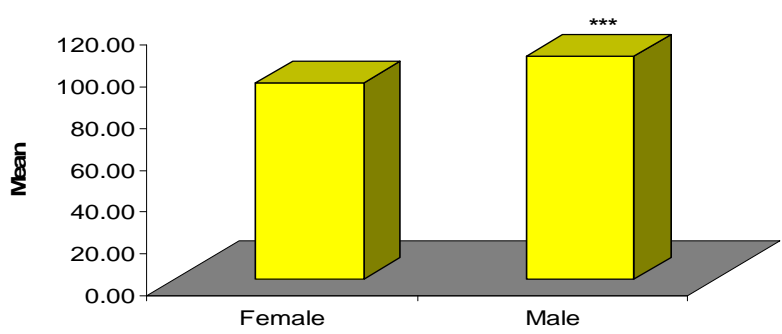

Figure 2: Comparison of length of mesostermum between 2 to 15 yrs females and males.

***p<0.001- as compared to Female

Length of sternum (mm)- 2 to 15 yrs

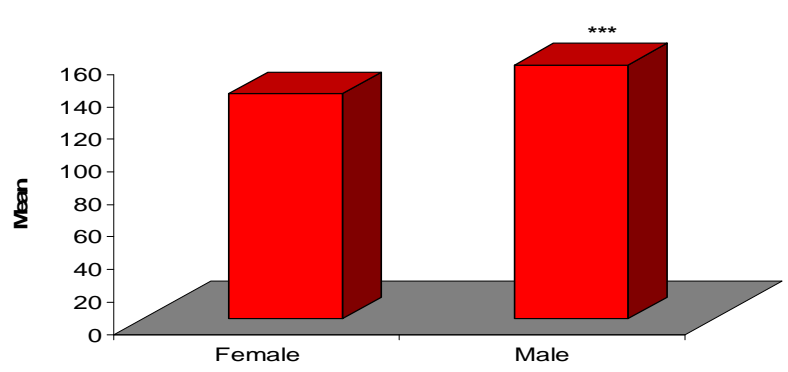

Figure 3: Comparison of length of sternum between 2 to 15 yrs females and males.

***p $<0.001$ - as compared to Female
Discussion

The aim of the present study was to evaluate the gender through measurement of children (M/F) sternum in Lucknow city of Uttar Pradesh, India. Results from our study revealed that body weight, BMI, and abdominal circumference were in normal range. The findings suggest that osteometric evaluation of the sternum can be an effective method for identification of sex in the Lucknow population as well as Uttar Pradesh.

\section{Comparison between Female vs. Male- 02-15 yrs:}

The comparison of mean length of manubrium, mesosternum and sternum between 2 to 15 yrs female and male was Comparing the mean length of manubrium, mesosternum and sternum between two groups, Student's t test showed significantly different and higher length of manubrium $(10.1 \%)(44.47 \pm 5.79$ vs. $49.45 \pm 3.45, \mathrm{t}=5.23$, $\mathrm{p}<0.001)$, mesosternum $(12.0 \%)(93.90 \pm 7.92$ vs. $106.71 \pm$ $6.25, \mathrm{t}=8.98, \mathrm{p}<0.001)$ and sternum $(11.4 \%)(138.38 \pm 6.93$ vs. $156.16 \pm 5.26, \mathrm{t}=14.45, \mathrm{p}<0.001)$ in males as compared to females.

According to observation and result in my present study it was fully supported the previous researchers, who has done the work in morphometry of sternum bone in cadaver and skeletal of human, because they told that the sterna has distinguish in different zone of India, as well as it is shorter than European country.

On the basis of above observation and result we can discus that [Ashley GT -1956b] got $52.2 \mathrm{~mm}$ for males and 47.9 $\mathrm{mm}$ for females. ${ }^{[8,9]}$ [Queiroz A et al., 2004] obtained 51.73 $\mathrm{mm}$ for males and $48.42 \mathrm{~mm}$ for females, which agreed with our findings of manubrium was $49.45 \pm 3.45 \mathrm{~mm}$ for male and $44.47 \pm 5.79 \mathrm{~mm}$ for female children respectively. From the parameters used in this study, the length of the manubrium distinguishes $10.1 \%$ in males is longer than females. This observation indicates that the difference between the average length of the male and female manubrium is $5.23 \mathrm{~mm}$, which is statistically significant $(\mathrm{P}<0.001)$ with the length of the male manubrium being longer than that of the female. According to 149 rules [Fernandez ED et al., 2007] the male length of mesosternum was $106.79 \mathrm{~mm}$ and $93.90 \mathrm{~mm}$ for females respectively. ${ }^{[6]}$ His findings were supported by, ${ }^{[7,11]}$ [Camps FE et al., 1976 
\& Bass WM 1987].

In the present study it was found that the male children sterna were longer than female children respectively from $156.16 \mathrm{~mm}$ and $138.38 \mathrm{~mm}$, where the average difference was $14.45 \mathrm{~mm}$ which is statistically significant $(\mathrm{P}<0.001)$ with the length of the male children sternum being longer than that of the female children. Thus study done by morphometry of children sternum were fully supported those previous researches, which was done in the European country as well as India, whereas much more need for this type of study.

\section{Conclusion}

On the basis of observations and results of my present study, evaluation of Sex in male and female children, through measurement of sternum in Lucknow city of Uttar Pradesh was concluded that - The basic characteristics of 02-15 yrs in males and female like age, height, weight, chest circumference, waist circumference and hip circumference and BMI was in normal range respectively.

The comparison of mean length of manubrium, mesosternum and sternum between 2 to $15 \mathrm{yrs}$, female and male sternum between two groups, significantly different and higher length of manubrium, mesosternum and sternum in males as compared to females children.

Thus the present results in my study was provide full support, study done by[12][Ashley GT-1956b] formulated the 149 rule, according to which a male sternum exceeded $149 \mathrm{~mm}$ in length whereas the female sternum was less than $149 \mathrm{~mm}$.

\section{Statistical analysis:}

Data were summarized as Mean \pm SD (standard deviation), range (min to max) and median. Groups were compared by independent Student's t test. Pearson correlation was done to assess association between variables. A two-tailed $(\alpha=2)$ $\mathrm{p}<0.05$ was considered statistically significant. Analyses were performed on SPSS software (windows version 21.0). The statistical analysis has been done by Dr M.P. Negi, from Central Drug Research Institute (CDRI) Lucknow.

\section{Acknowledgement:}

The authors are grateful to all subjects who participated in this study. I would like to thanks Dr. M.P. Negi, Statistician in Central Drugs Research Institute (CDRI), Lucknow for his Statistical analysis and cooperation, and I would like to give specially Thanks Dr. Navneet kumar, Professor \& Head, department of Anatomy, King George's Medical University, U.P., Lucknow for developing this hypothesis, cooperation, and conducting this research work.

\section{References}

1. Macaluso PJ, Lucena J. Estimation of sex from sterna dimensions derived from chest plate radiographs in contemporary Spaniards. Int J Legal Med.2014; 128(2):389-95.

2. Dwight T. The sternum as an index of sex and age. J Anat. 1881; 15:327-30.

3. Osunwoke EA, Gwunireama IU, Orish CN, Ordu KS, Ebowe I. A study of sexual dimorphism of the human sternum in the southern Nigerian population. J Appl Biosci 2010; 26:1636-9.

4. Torwalt CR, Hoppa RD. A test of sex determination from measurements of chest radiographs. J Forensic Sci. 2005; 50:78590.

5. Singh J, Pathak RK, Singh D. Morphometric sex determination from various sternal widths of Northwest Indian sternums collected from autopsy bones: Egypt J Forensic Sci. 2002; 2(1):18-28.

6. Dahiphale VP, Baheete BH, Kamkhedkar SG. Sexing the Human Sternum in Marathwada Region. J Anat Soc India. 2002; 51(2): 162-167.

7. Camps FE. Editor Gradwohl's legal medicine. 3rd ed. Bristol. John Wright \& sons Ltd; 1976. p. 110.

8. Ashley GT. A comparison of human and anthropoid mesosterna. American Journal of Physical Anthropology.1956; 14(3):449-61.

9. Queiroz A, Wada RB, Preza A, Spadacio C, Cruz BDL. Sex determination by weight verification of sternum bone Brasil. Forensic Med Costa Rica 2004; 22:1-7.

10. Fernandez ED, Saez AS, Moro JIM. Determinacion antropologica del sexo a traves del esternon: Anthropological determination of sex by studying the sternum. Revista de la Escuela de Medicina Legal 2007; 1-16.

11. Bass WM. Human Osteology: A Laboratory and Field Manual of the Human Skeleton (3rd Ed.). Missouri Archaeological Society Special Publications, Columbia, Missouri. 1987: p. 112;

12. Ashley GT, The human sternum - the influence of sex and age on its measurement. Journal of Forensic Medicine 1956b; 3: 27-43.

Copyright: ( $)$ the author(s), publisher. Academia Anatomica International is an Official Publication of "Society for Health Care \& Research Development". It is an open-access article distributed under the terms of the Creative Commons Attribution Non-Commercial License, which permits unrestricted non-commercial use, distribution, and reproduction in any medium, provided the original work is properly cited.

How to cite this article: Sharma SV, Pankaj AK, Kumar N, Nilesh, Sharma HB. Evaluation of Gender in Living Male and Female Children Through the Measurement of Sternum Bone in the Population of Uttar Pradesh. Acad. Anat. Int. 2019;5(1):21-24.

DOI: dx.doi.org/10.21276/aanat.2019.5.1.6

Source of Support: Nil, Conflict of Interest: None declared. 